\title{
A Study on Transformational Leadership for Senior High School Principals: An Institutional Research Approach
}

\author{
Shu-Fang Lin, Baisu Takiludun, and Hung-Chang Chang
}

\begin{abstract}
This study explores the content of Institutional Research (IR) and its application on transformational leadership for school principals. The study conducted a case study of a senior high school in Taiwan to explore the application of empirical results of IR on practicing transformational leadership. On the ground of a three-aspect literature review of senior high school institutional work, IR, and school principal transformational leadership, the study employed QlikView, a business intelligence exploration software, to analyze student data of enrollment, learning achievement, and absenteeism in a senior high school. The study asked two research questions: (1) how to conduct an empirical IR based on institutional data of a senior high school? (2) how does a senior high school principal apply the empirical results of IR to practice transformational leadership? Based on the aforementioned empirical results of IR, the study delved into meanings behind statistic figures, and attempted to retrace possible origins of problems. The study hopes to demonstrate a practical model of decision making grounded on IR and empirical results of a high school principal and contribute to pave the way to transformational leadership of institutes.
\end{abstract}

Index Terms-Institutional research (IR), senior high school, secondary education, transformational leadership.

\section{INTRODUCTION}

Bill Gates once said that Microsoft is always 18 months away from bankruptcy. With sense of huge risk, Microsoft keeps proactive in achieving their goals and successfully establishes a kingdom of software enterprise. Innovation and efficiency are actually both crucial to business and educational success. Accordingly, schools should be the origin of creative ideas and practice. Students need to be inspired to think creatively and differently instead of reciting or replicating. In other words, they need future capacity. However, how can schools achieve their goals of innovation and efficiency? Principals as the leader of schools are encouraged to take action of transformational leadership and try their best to keep schools improving and making progress.

In 1940, Institutional Research (IR) was proposed to effectively deal with America Universities' management issues. Institutional research has become an important strategy for universities in United States for more than 70 years. Most U.S. universities have dedicated offices of institutional research to be responsible for IR and then to

Manuscript received January 15, 2019; revised February 25, 2019.

Shu-Fang Lin is with Department of Educational Policy and Administration of National Chi Nan University, Taiwan (e-mail: shoufanglin1@gmail.com).

Baisu Takiludun and Hung-Chang Chang are with Department of Educational Policy and Administration of National Chi Nan University Taiwan (e-mail: baisu1103@gmail.com, treeb.chc@gmail.com). improve school administration and management with evidence-based suggestion. Volkwein [1] thinks that there are three concepts involving IR critical to school management: (1) school affairs reports and strategies analysis; (2) planning, student recruitment, and financial management; (3) quality assurance, learning achievement assessment, program evaluation, efficacy and certificates (Webber, Calderon, Nauffal, Saavedra, Bramblett, \& Borden [2]). Being faced up numerous educational challenges, Taiwan Association for Institutional Research (TAIR) established in the Jan. of 2016. It is believed that IR concepts and trends will start to grow stronger and stronger theoretically and empirically in Taiwan. In this study, we try to explore the content of Institutional Research (IR) and its application on transformational leadership for school principals. Specifically speaking, we conducted a case study of a senior high school in Taiwan to explore the application of empirical results of IR on practicing transformational leadership.

Accordingly, this paper explores two questions namely; (1) how to conduct an empirical IR based on institutional data of a senior high school? (2) how does a senior high school principal apply the empirical results of IR to practice transformational leadership?

\section{LITERATURE REVIEW}

\section{A. Senior High School Institutional Work}

Daily routine works in a senior high school are quite trivial but well organized. Senior high school institutional works mainly center in instruction and learning, however based on philosophy, administration, environment, equipment and so on. According to Taiwan's 2015 senior high schools' school evaluation program, schools need to perform well in the below 8 areas, including (1) the principal's educational philosophy (2) administration and management strategies (3) curriculum and instruction (4) teachers' quantity and quality (5) students' affairs and guidance (6) community (7) environment and equipment (8) practice and consulting / professional departments. All above areas ought to put into practice effectively and efficiently. The structure of school evaluation content is as Fig. 1 shows (Senior high school evaluation [3]).

\section{B. Institutional Research}

What is IR? Defining IR is not an easy task. Most definitions emphasize the functional aspects of IR and note that it is directed towards the support of management at an institution: 'what distinguishes institutional research stricto sensu is its application to the individual establishment of higher education' (Neave [4]). Saupe [5] provides a similar 
and highly influential definition of IR: 'research conducted within an institution of Studies in Higher Education 457 higher education in order to provide information which supports institutional planning, policy formulation and decision making'. There have also been efforts to provide a generalized definition that is broad enough to accommodate various functions and characteristics of IR. Terenzini [6] considers IR to be 'organizational intelligence; that is to say, IR researchers conduct researches based on institution's needs to gather data, analyze, transform into information, and provide evidence-based strategies. Moreover, three concepts involving IR were critical to school management: (1) school affairs reports and strategies analysis; (2) planning, student recruitment, and financial management; (3) quality assurance, learning achievement assessment, program evaluation, efficacy and certificates (Webber, Calderon, Nauffal, Saavedra, Bramblett, \& Borden [2]).

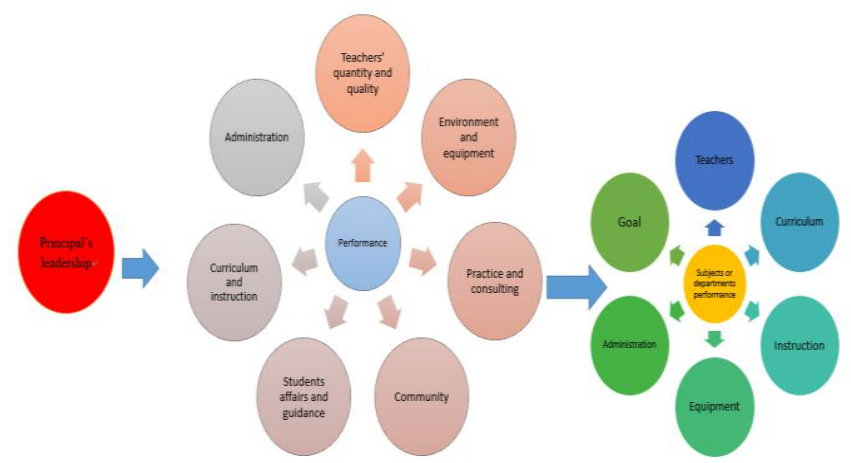

Fig. 1. Taiwan's 2015 senior high schools' school evaluation program These items of school-evaluation program point out the important tasks for senior high schools. In other words, that means senior high schools need to adopt those tasks or works into their scope of school institutional works.

Additionally, based on experience in Europe and Australasia, it is possible to outline an alternative functional typology for institutional research: (1) Routine institutional management, including formal internal and external reporting and operations support. (2) Strategy formation, including modeling and scenario planning. (3) Quality assurance and quality enhancement. (4) Marketing and competitive data analysis (John Taylor, Martin Hanlon \& Mantz Yorke [7]).

The development of AIR stimulated the emergence of similar regionally based organizations elsewhere, such as the Europe (EAIR), the South East Asian era (SEAAIR), Australia, southern Africa, the Philippines, and Puerto Rico. However, the emphasis of these groups vary widely based on their research goals. In Taiwan, more and more universities involve themselves in IR work, such as National Sun Yat-sen University, Asia University, Shih Hsin University, National University of Kaohsiung, Soochow University and Chang Gung University of Science and Technology. Those universities design their own framework and analysis system of IR and then conduct IR work to respond to school management needs. In spite of harsh challenges as senior high schools confront; however, much less senior high schools than universities try to apply IR to form evidence-based strategies and decision. In such situation, this study hopes to demonstrate a practical model of decision making grounded on IR and empirical results of a high school principal and contribute to pave the way to transformational leadership of institutes.

\section{Transformational Leadership}

Transformational leadership is a popular conception of leadership which has been investigated in both educational and business contexts. According to Bass and Avolio [8], a transformational leader forms an organizational vision which goes beyond existing systems and practices. Leader needs to take risks to encourage and initiate change or innovation. Moreover, leaders should support and motivate their followers to exceed their original goals and successfully create an organizational climate which respects individual needs and differences. Through collaboration or cooperation, leaders and followers start to trust each other and eventually focus on the common good and the accomplishment of the goals of the school or organization.

Accordingly, transformational leadership in fact refers to a process which changes and converts individuals and organizations. Specifically, transformational leadership refers to the leaders' ability to prompt followers to want to change and improve. It involves the evaluation of motives and needs of members of the organization and the satisfaction of their needs. Transformational leadership is the process through which an individual commits himself/herself to the well-being of the organization and creates connections which increase the level of motives and morale of subordinates (Maria \& Androula [9]).

Bass and his colleagues (see, for example, Bass \& Avolio [10]) proposed five factors as the main dimensions of transformational leadership:

A. Attributed idealized influence (the degree to which followers consider leaders to be trustworthy, with charisma, a clear and attainable mission, and a vision for the organization).

B. Idealized influence as behavior (actual leader behavior characterized by values and a sense of purpose).

C. Inspirational motivation (the behavior of the leader which serves as a source of inspiration for followers by providing them with meaning and challenge).

D. Intellectual stimulation (leaders encourage followers to be creative and innovative so that they adopt a critical stance in relation to prevalent assumptions and traditions).

E. Individualized consideration (leaders focus on individual needs and deal with followers on a one-to-one basis).

Transformational leadership occurs when, in their interactions, people "raise one another to higher levels of motivation and morality. Transforming leadership ultimately becomes moral in that it raises the level of human conduct and ethical aspiration of both the leader and the led, and thus it has a transforming effect on both" (Burns [11]). Leaders motivate followers or members by making them more aware of the importance of task outcomes, inducing them to transcend their own self-interest for the organizations or schools, and inducing their higher-order needs to develop.

Which parts in schools might be involved with transformational leadership? Transformational leadership was found an impact on teachers' perceptions and behavior (Bogler [12]; Griffith [13]; Leithwood \& Jantzi [14]) and 
linked to the commitment of employees to the organization, their trust in their leader, their job satisfaction and their motivation to learn. Particularly, in education, it seems to affect teachers' attitudes towards their school, and their commitment to change and learning (Bass [15]; Hallinger [16]). Accordingly, it might be worthy of more researches on transformational leadership and more trials to explore how to put principals' transformational leadership into action.

In this study, we try to conduct an empirical IR based on institutional data of a senior high school and then try to demonstrate how a senior high school principal can apply the empirical results of IR to practice transformational leadership.

\section{Methodology}

\section{A. Research Process}

The first stage was the exploratory stage. After reference to researchers' empirical experience in senior high school and literature research, more information and ideas about IR concept or experiments were brought into this study. After this exploratory stage is the analytic stage, we tried to conduct an IR experiment in a senior high school. Then came the application stage, after taking action to conduct IR experiments, we tried to form strategies for principal's transformational leadership. Fig. 2 showed the process of this study.

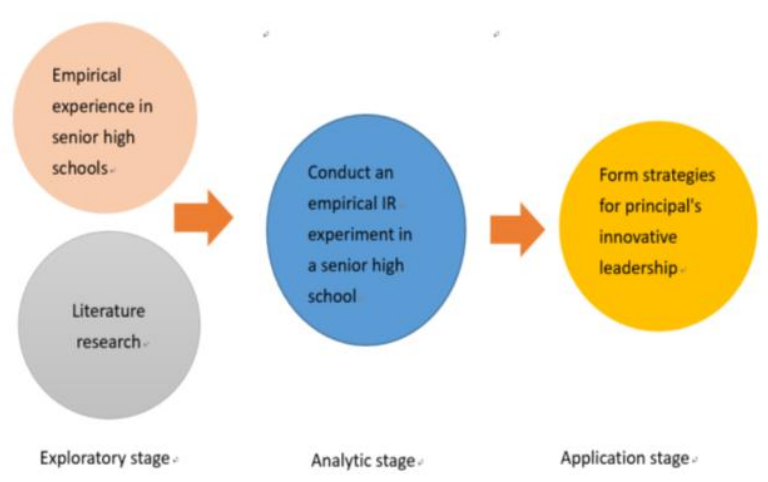

Fig. 2. The research method and process.

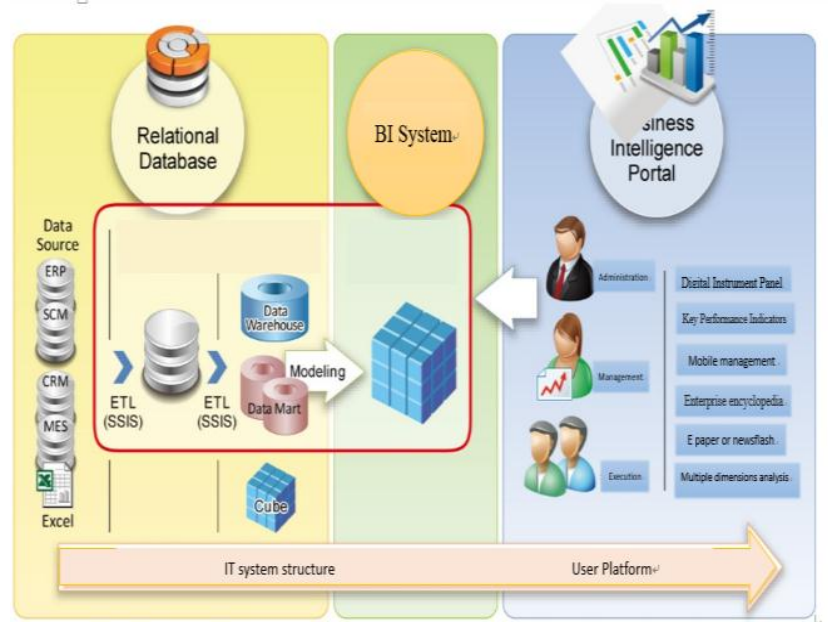

Fig. 3. The application of BI analytic software http://tw.digiwin.biz/softwareListDetail_P2012 111250711_PA201308202329.html[17].

\section{B. Research Instrument}

This study designed an IR model for a senior high school and used Business Intelligence(BI) analytic software titled "Qlikview") to integrate school administration system and to design analysis situations. Research data were directly extracted from school administration system's database Fig. 3 showed the application of BI analytic software in the study.

QlikView was a extensively adopted BI platform for turning data into knowledge. Its simplicity allowed more than 24,000 organizations worldwide to easily consolidate, search, and visually analyze all their data for unprecedented business insight QlikView friendly promotes unrestricted analysis of application data by doing what, helping users make time-saving and accurate decisions. (Visual Intelligence Qlik Business Intelligence Experts [18]).

With its practical traits, QlikView is also quite user friendly. Unlike other BI platform, when a user opens a QlikView application, data is visible right away, without specifying any parameters. The user interacts with the interface to step through the data in an exploratory way, to zero in on specific results (Troyansky, Gibson, Leichtweis, and Bjork [19]).

\section{Research Site and Sample}

The rural school in this study is located in central Taiwan and offers a variety of courses for students, including comprehensive high school, mathematical experiment class, language experiment class, occupation class, practical skills courses, school of continuing education.

The study was conducted in one medium-size high school in central Taiwan. The study sampled 1134 students from the school, including students of both genders and all grades. The students aged from 15 to 18 -year-old.

\section{RESUlTS AND DisCUSSION}

\section{A. Conduct an Empirical IR Based on Institutional Data of a Senior High School}

We conduct an empirical IR in a senior high school in Taiwan and try to find out the meanings behind numbers.

\section{1) The analysis of students' enrollment}

Analyzing students' enrollment to help principals get a picture of the increasing or decreasing trends in different enrollment (academic) years and school districts. Fig. 4, 5 and 6 show the students' enrollment situation of a senior high school in Taiwan. The main source of students exists in the neighborhood and some students come from another bigger city next to the county where this school is located. From Figure 5, we can understand more specifically about different department's students' sources. Furthermore, Figure 6 helps to recognize different junior high schools students' enrollment. This analysis will be more specific for principals and after this analysis, they will know where the target junior high schools are for their next step in students' recruitment. With good understanding of all students' enrollment data, principals can revise or reform their strategies for students' recruitment. 


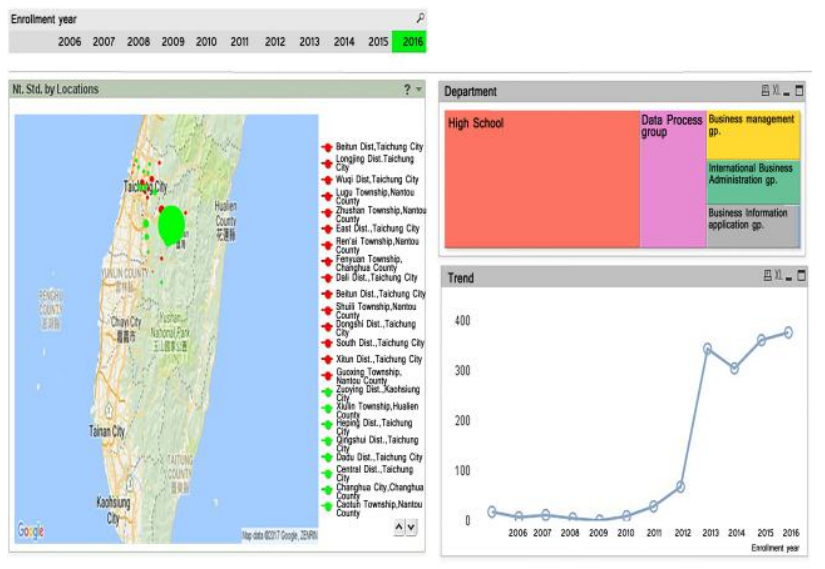

Fig. 4. The analysis of students' enrollment (Google Map).

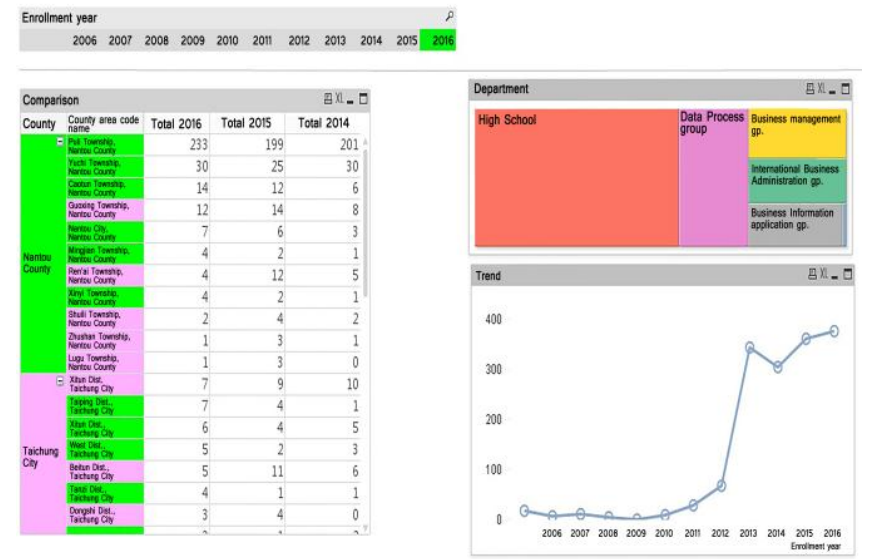

Fig. 5. The analysis of students' enrollment (Table Form).

\begin{tabular}{|c|c|c|c|c|c|}
\hline \multicolumn{6}{|c|}{ 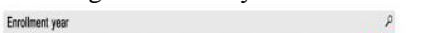 } \\
\hline \multicolumn{3}{|c|}{ camerason } & \multicolumn{3}{|c|}{ 811.0 } \\
\hline \multicolumn{6}{|c|}{ 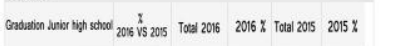 } \\
\hline \multicolumn{6}{|c|}{$4 \% \quad 37660000 \% \% \quad 362100000 \%$} \\
\hline Jit & $20 \%$ & $1303457 \%$ & \\
\hline N12 & $19 \%$ & 6818098 & \multirow{2}{*}{\multicolumn{3}{|c|}{57.1575}} \\
\hline HH3 & $.9 \%$ & $48127 \%$ & \multirow{2}{*}{\multicolumn{3}{|c|}{5314648}} \\
\hline IH4 & $40 \%$ & $10266 \%$ & & & \\
\hline HHS & $.18 \%$ & 92996 & \\
\hline JH6 & $100 \%$ & $61.00 \%$ & \multicolumn{3}{|c|}{1133048} \\
\hline VHT & $20 \%$ & $61.00 \%$ & \multicolumn{3}{|c|}{$\begin{array}{ll}3 & 0.83 \% \\
2 & 055 \%\end{array}$} \\
\hline Hite & & $5133 \%$ & \\
\hline \multirow{2}{*}{\multicolumn{6}{|c|}{ 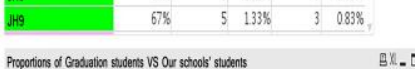 }} \\
\hline & & & & & \\
\hline \multicolumn{6}{|c|}{ 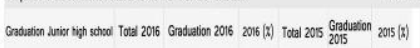 } \\
\hline \multicolumn{6}{|c|}{$\begin{array}{llllll}376 & 216688 & 0 \% & 362 & 1 & 0 \%\end{array}$} \\
\hline & & & 101 & & \\
\hline HII & 68 & 2492776 & 57 & 0 & \\
\hline HII3 & 48 & $378 \quad 136$ & 53 & & \\
\hline 西 & & 22056 & 2 & 0 & \\
\hline & & $78 \quad 12 \%$ & 11 & & \\
\hline Jith & & $561 \quad 16$ & 3 & & \\
\hline & 6 & $454 \quad 16$ & 2 & & \\
\hline & 5 & $40 \quad 13 \%$ & 3 & & $8 \%$ \\
\hline HII9 & 5 & $24 \quad 218$ & & & \\
\hline
\end{tabular}

Fig. 6. The analysis of students' enrollment (Different Graduation Junior High Schools)

\section{2) The analysis of students' absence}

The analysis of students' absence is as Fig. 7. shows. It allows principals to perceive their students' absence performance the reasons why students leave classrooms. Some reasons of absence are beneficial to students' achievement and the others are not. As a principal, s/he needs to get a clear picture of her or his students' absent records and forms creative and useful strategies to lead her or his staff to improve students' positive performance behaviorally.

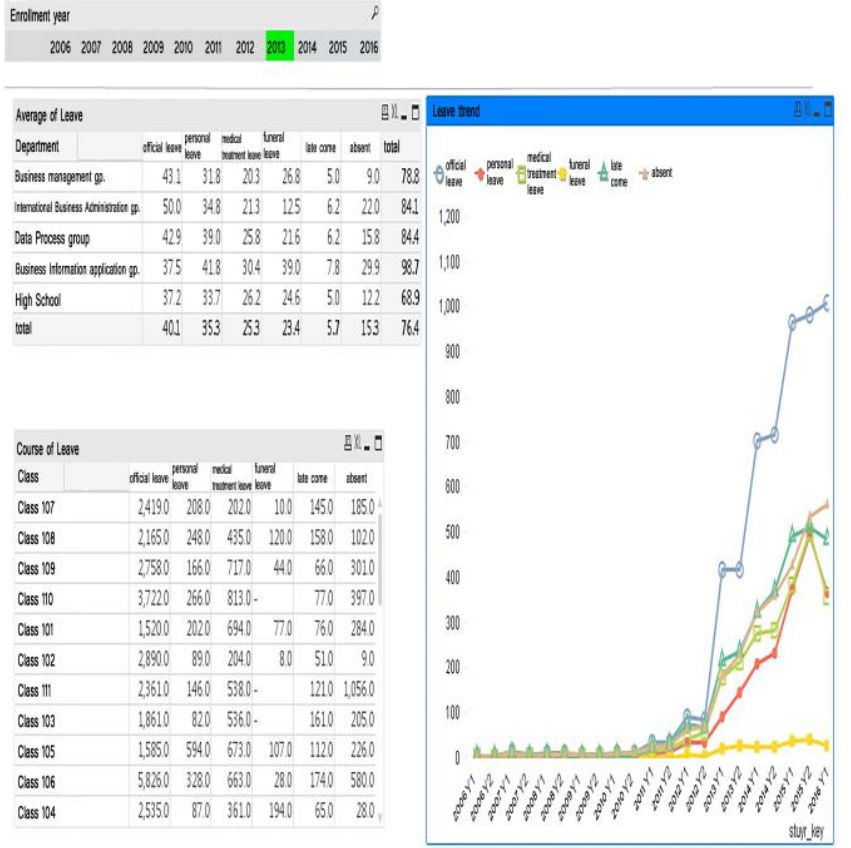

Fig. 7. The analysis of students' absence.

\section{B. The way that a senior high school principal can apply} the empirical results of IR to practice transformational leadership.

The main concept of transformational leadership is that leaders can motivate and encourage members to achieve particular outcomes by developing their leadership potential, growing together and elevating each other's moral and motivational levels, taking into account both individual needs and groups' goals to achieve mutual growth. A leader with transforming leadership can increase the confidence of members and enhance the value of the work results in order to inspire members to do more than they originally expected. Through the establishment of forward-looking vision, the display of personal charm, the use of various incentive strategies to enhance members work motivation and job satisfaction, a leader can stimulate members willing to pay extra efforts to achieve their goals. Namely, leaders with transformational leadership emphasize forming vision, communicating vision, empowering autonomy, motivating and inspiring their members. They stress organizing culture climate and trust relationship, rather than emphasizing control or problem solving.

In Taiwan, senior high schools currently face the harsh challenges of low birth rates. In students' recruitment issue, senior high schools were challenged not only by the quantity of students but also quality. Student's diversity especially increases the difficulty of follow-up instruction and guidance works. As school leaders, what can principals do to lead school teachers and administrative teams to shape the vision of the school, improve instructional quality, student adaptation quality, student learning outcomes, and then achieve the goal of school organization? "Institutional research" is a new school management strategy in Taiwan at present. In particular, most of the senior high schools are still unfamiliar with it. In this study, we introduce the concept of "Institutional research" and conduct an experiment to produce some results of school affairs analysis, helping the principal's developing innovative strategy of implementing 
transformation leadership. In the "Student Source Analysis" section, the principal can present specific charts and data to help the staff understand the main source of students, to explore whether students have a regional identity, a specific community culture, or even their family background. Before students' admission, teachers can grasp the characteristics of students and adjust instructional method and strategies. "Performance Analysis" represents the instructional and learning outcomes or achievements in the classrooms. Through the presentation of specific figures, we can understand the direction of future goal of instructional improvement and adjustment. "Students' absence analysis" can help to understand students' stability in the classrooms. This analysis can help to assess the need of students' activities adjustment or students' need for guidance intervention, and so on.

Through the use of institutional research, the principal can completely demonstrate the role of innovation and change. Institutional research's characteristics of specific school-oriented, data-oriented will help the administrative teams and teachers to understand the efficacy of students' recruitment, the effectiveness of instruction, students' learning and adapting themselves to school life. After that, the administrative teams and teachers will take more in-depth participation in school development and vision shaping process. Further, the institutional research works can meet the needs of teachers, administrative colleagues, and even students to raise research topics and process research works. In this way, principals, the school leaders, will be able to motivate school members to participate in the schools, empower their autonomy, inspire the staff, create a change for innovative and trust organization culture, and eventually display transformational leadership by taking advantage of the strategies of institutional research.

\section{REFERENCES}

[1] F. Volkwein, Teaching and Learning in IR Courses: Myths vs. Reality, Paper presented at the forum of the association for institutional research, Denver, CO, 2015.

[2] K. Webber, A. Calderon, D. Nauffal, M. Saavedra, S. Bramblett, and V. Borden, IR in the World Around Us, paper presented at the Forum of the association for Institutional Research, Denver, CO, 2015.

[3] Senior high school evaluation. (2015). The third stage of Senior high school evaluation programs: Ordinary senior high schools, bilateral high schools, magnet senior high schools. [Online]. Available: http://qoi.nknu.edu.tw/TeachingEva/User/ Default.aspx.

[4] N. Guy, "Institutional research: From case study to strategic instrument," Roddy Begg, pp. 3-14, 2003.

[5] J. L. Saupe, The Functions of Institutional Research, Tallahassee, FL: Association for Institutional Research, 1990.
[6] T. T. Patrick, "On the nature of institutional research and the knowledge and skills it require," Research in Higher Education, vol. 34, no. 1, pp. 1-10, 1993.

[7] J. Taylor, M. Hanlon, and M. Yorke, New Directions for Institutional Research, no. 157, 2013.

[8] B. M. Bass and B. J. Avolio, "Improving organizational effectiveness through transform-ational leadership," Thousand Oaks, CA: Sage Publications, 1994

[9] E. M. Maria and I. Androula, "The link between transformational leadership and teachers' job satisfaction, commitment, motivation to learn, and trust in the leader," Academy of Educational Leadership Journal, vol. 20, no. 3, pp. 12-22, 2016.

[10] B. J. Avolio and B. M. Bass, Multifactor Leadership Questionnaire Manual, Lincoln, Nebraska: Mind Garden, Inc, 2004.

[11] J. M. Burns, Leadership, New York: Harper \& Row, 1978.

[12] R. Bogler, "The influence of leadership style on teacher job satisfaction," Educational Administration Quarterly, vol. 37, no. 5, pp. 662-683, 2001.

[13] J. Griffith, "Relation of principal transformational leadership to school staff job satisfaction, staff turnover, and school performance," Journal of Educational Administration, vol. 42, no. 3, pp. 333-356, 2004.

[14] K. A. Leithwood and D. Jantzi, "Transformational school leadership for large-scale reform: Effects on students, teachers, and their classroom practices," School Effectiveness and School Improvement, vol. 17, no. 2, pp. 201-227, 2006

[15] B. M. Bass, "Two decades of research and development in transformational leadership," European Journal of Work and Organizational Psychology, vol. 8, no. 1, pp. 9-32, 1999.

[16] P. Hallinger, "Leading educational change: Reflections on the practice of instructional and transformational leadership," Cambridge Journal of Education, vol. 33, no. 3, pp. 329-351, 2003.

[17] DING SIN computer Co., Ltd (2016). [Online]. Available: http://tw.digiwin.biz/ software ListDetail_P2012111250711 PA201308202329.html.

[18] Visual Intelligence - Qlik Business Intelligence Experts. (2016) [Online]. Available: https://www.visualintelligence.co.nz/qlikview/

[19] O. Troyansky, T. Gibson, C. Leichtweis, and L. Bjork, QlikView Your Business: An Expert Guide to Business Discovery with QlikView and Qlik Sense, Wiley, 2015.

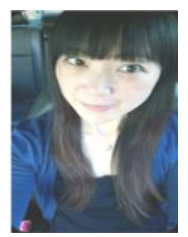

Shu Fang Lin was born in Yun-Lin, Taiwan. She is currently a PhD student at the Department of Educational Policy and Administration of National Chi Nan University Taiwan since 2015.

She is also a teacher in the Affiliated Senior High School of National Chi Nan University Taiwan.

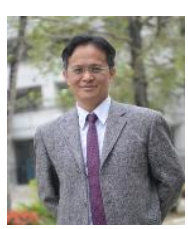

Baisu Takiludun was born in Nantou, Taiwan. He is a PhD student at the Department of Educational Policy and Administration of National Chi Nan University Taiwan.

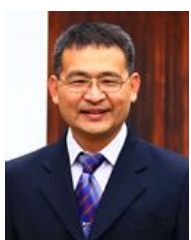

Hung-Chang Chang was born in Changhua, Taiwan He is a PhD student at the Department of Educational Policy and Administration of National Chi Nan University Taiwan.

$\mathrm{He}$ is also a principal of Changhua county Ping $\mathrm{He}$ elementary school Taiwan. 